УДК [ 005: : 65.011.2] : :[355.311.1/3+355.431]

Ігор Сергійович Романченко (доктор військ. наук, професор,)

Володимир Петрович Котляров (доктор техн. наук, професор) ${ }^{1}$

Олександр Олексійович Павлюк ${ }^{2}$

${ }^{1}$ Центральний науково-дослідний інститут Збройних Сил Украӥни, Київ, Украӥна
${ }^{2}$ Військова частина А0796, Рівне, Украӥна

\title{
ВИЗНАЧЕННЯ АНАЛІТИЧНОЇ ЗАЛЕЖНОСТІ ДЛЯ ПОЧАТКОВОГО СПІВВІДНОШЕННЯ СИЛ СТОРІН 3 УРАХУВАННЯМ КРИТЕРІАЛЬНИХ ОБМЕЖЕНЬ
}

У статті запропоновано підхід, який трунтується на аналізі системи диференціальних рівнянь методу динаміки середніх для визначення загальної аналітичної залежності співвідношення сил сторін 3 урахуванням критеріальних обмежень. Рівняння динаміки середніх розглядаються в нелінійній постановиі, коли коефіиієнти уражаючого впливу залежать від чисельності станів.

У статті використовуються підходи теорії диференџіальних рівнянь для визначення загальної інтегральної згортки (загального інтеграла системи).

Критеріями досягнення мети операції у цілому є величина припустимих втрат однієї зі сторін та потрібна величина співвідношення сил сторін. 3 урахуванням критеріальних обмежень запропонований підхід дозволяє визначити необхідний час на проведення операщіï, а також, у випадку необхідності, - $i$ початкове значення потрібної кількості сил однієї зі сторін для гарантованого досягнення мети операції в иілому.

Розв'язання системи диференціальних рівнянь дозволяє розрахувати еталонний графік (опорну траєкторію) зміни коефіцієнта співвідношення сил сторін у часі з дотриманням умов критеріальних обмежень.

Ключові слова: угруповання військ (сил), співвідношення сил сторін, критеріальне обмеження, диференціальне рівняння.

\section{Вступ}

Постановка проблеми. Дослідження в напрямі розвитку та підготовки збройних сил до оборони країни, підтримання їх в необхідному складі з метою забезпечення відбиття нападу та розгрому агресора при розв’язанні ним війни потребують виконання значних за обсягом розрахунків, до яких, поряд із розрахунками щодо визначення ступеня небезпеки угруповань противника, належать i розрахунки щодо визначення потрібної кількості сил і засобів для виконання визначених завдань.

У цій галузі досліджень використовувались i використовуються методи оцінювання співвідношення сил, які належать до традиційних форм ведення збройної боротьби (операцій i бойових дій). У рамках зазначених форм одне одному протидіють угруповання військ, причому передбачається, що кожна зі сторін конфлікту готова досягти своєї мети. Сторона, що здійснює наступ, - розгромити угруповання противника та захопити його територію, а інша - послабити наступ противника, перебуваючи в обороні, і потім завдати йому поразки в ході контрнаступу (контрудару). При цьому протидіючі сторони для досягнення своїх цілей повинні враховувати співвідношення сил, що склалося між ними.

Під час оцінювання цього параметра особливої актуальності набувають питання визначення потрібного початкового співвідношення сил для гарантованого досягнення мети операції в цілому за заданими критеріями.

Аналіз останніх досліджень і публікацій. Необхідно підкреслити, що існуючі методики розрахунку співвідношення сил грунтуються на оцінюванні бойових можливостей протидіючих угруповань, які знаходять шляхом додавання їх бойових потенціалів. Тоді припустиме початкове співвідношення сил сторін знаходиться із урахуванням величини коефіцієнта бойової достатності. У цьому випадку з прогнозованого характеру збройної боротьби визначають дольову участь i, як наслідок, необхідні бойові потенціали видів та родів військ збройних сил, а також компонентів, що входять до них, а потім розраховують і бойовий склад їх угруповань.

Однак, що стосується величини коефіцієнта бойової достатності, то вона зазвичай визначається на основі досвіду війн і воєнних конфліктів і має достатньо широкий діапазон змінення. До того ж, ця статистична задача має деяку незавершеність i щодо зв'язку необхідного початкового співвідношення сил із кінцевим значенням відповідних показників на момент завершення бойових дій. Частково це питання розв'язано в роботі [1], де центральне місце посідає модель ведення двосторонніх бойових дій угруповань у конфлікті сторін на основі лінійних

(C) І.С. Романченко, В.П. Котляров, О.О. Павлюк

Modern Information Technologies in the Sphere of Security and Defence $\mathcal{N} N$ 3 3(33)/2018 ISSN 2311-7249(Print)/ISSSN2410-7336(Online) 
диференціальних рівнянь динаміки середніх 3 незмінними залежностями уражаючого впливу. Однак практика застосування військ (сил) та результати імітаційного моделювання операції (бойових дій) встановлюють більш складний (нелінійний) характер вказаних залежностей, неврахування яких 3 плином часу значно знижує точність розрахунків. Крім того, робота [1] не має логічної завершеності в плані встановлення однозначного зв'язку критеріальних обмежень с початковим значенням співвідношення сил сторін.

Метою статті $\epsilon$ побудова коректного алгоритму визначення аналітичної залежності для початкового співвідношення сил сторін 3 урахуванням критеріальних обмежень.

\section{Виклад основного матеріалу дослідження}

У загальному вигляді вихідну нелінійну систему методу динаміки середніх представимо у вигляді:

$$
\begin{aligned}
& \frac{d m_{A}}{d t}=-f_{B}\left(\lambda_{B}\right) \cdot m_{B} ; \\
& \frac{d m_{B}}{d t}=-f_{A}\left(\lambda_{A}\right) \cdot m_{A},
\end{aligned}
$$

де $m_{A}, m_{B}$ - кількість боєздатних одиниць угруповань сторін; $f_{A}\left(\lambda_{A}\right), f_{B}\left(\lambda_{B}\right)$ інтенсивності уражаючого впливу сторін; $\frac{d m_{A}}{d t}, \frac{d m_{B}}{d t}$ - динаміка змінення кількості боєготових одиниць сторін у часі.

На підставі підходу, який викладений в [2], функції $f_{A}\left(\lambda_{A}\right), f_{B}\left(\lambda_{B}\right)$ апроксимуються залежностями виду:

$$
\begin{aligned}
& f_{A}\left(\lambda_{A}\right)=\lambda_{A} \frac{m_{A}}{m_{B}} ; \\
& f_{B}\left(\lambda_{B}\right)=\lambda_{B} \frac{m_{B}}{m_{A}} .
\end{aligned}
$$

Традиційно, для визначення часових характеристик операцій (бойових дій), а також співвідношення сил сторін у часі необхідно розв'язати систему (1) за заданих початкових умов.

Установивши тепер критерій співвідношення сил сторін на момент завершення операції або її етапів, у принципі, за результатами розв'язування системи (1) вже можна ітераційним способом (варіюванням початкової чисельності однієї сторони) знайти таке вихідне співвідношення сил сторін, за якого необхідна мета операції буде досягнута.

Однак, відповідно до постановочної частини статті, все-таки сформулюємо наступну задачу досліджень як задачу знаходження такої залежності, яка б пов'язувала чисельності сторін та критеріальні обмеження в одному аналітичному виразі 3 урахуванням нелінійного характеру залежностей уражаючого впливу. Для цього скористаємося способами знаходження загальних інтегралів системи диференціальних рівнянь [3]. Тоді запис рівнянь у вигляді (1) дозволяє знайти один із таких інтегралів. Дійсно, виконуючи необхідні математичні викладки, одержимо:

$$
m_{A}^{4}=\frac{\lambda_{B}}{\lambda_{A}} m_{B}^{4}+C,
$$

де $C$ - довільна постійна інтегрування.

Вираз (3) справедливий для будь-якого моменту часу $\mathrm{i}$, таким чином, у загальному вигляді встановлює аналітичний зв'язок між чисельностями сил сторін. Залежність (3) має біквадратний характер i порівняно 3 [1] більш точно відображає нелінійний характер процесу. I дійсно, на рис. 1 наведено порівняння результатів чисельного моделювання системи (1) для випадків, коли у цій системі інтенсивності уражаючого впливу мають лінійний характер (крива $a$ ), а також нелінійний характер (крива $b$ ). Точками на рисунку позначені результати імітаційного моделювання, а коефіцієнт $K$ характеризує співвідношення сил сторін.

Практична збіжність значень, які отримані за нелінійною моделлю (крива $b$ ), 3 результатами більш точного детального імітаційного моделювання свідчить про коректність виразів у формах (2) і (3).

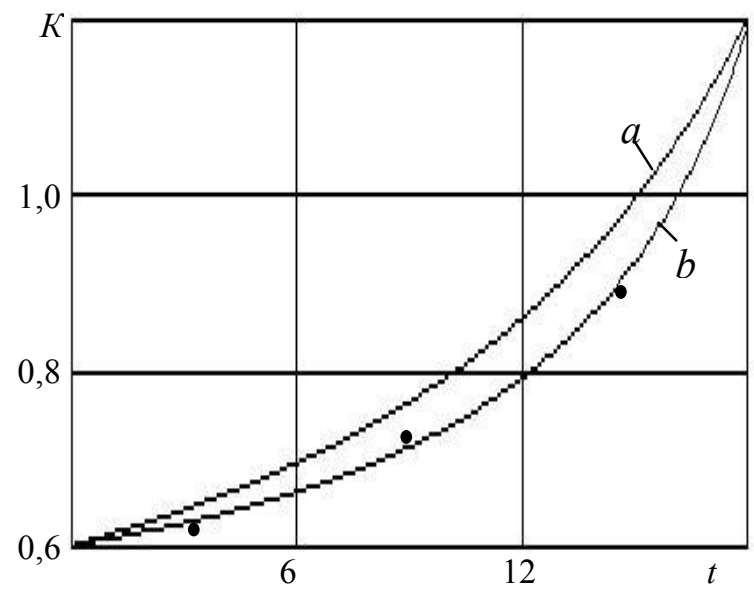

Рисунок 1 - Порівняння результатів

Що стосується постійної інтегрування $C$ у залежності (3), то вона незмінна як для початкового співвідношення сил сторін, так і для чисельностей сторін на кінець операції. Цим i скористаємось у подальшому. Тоді, виходячи із вимог нормативних документів, задамо через величини $m_{A}^{k}$ і $m_{B}^{k}$ (індекс $k$ позначає час завершення операції) таке співвідношення сил сторін на кінець операції $K^{k}$, яке нас задовольняє.

$$
\begin{array}{r}
\text { Введемо до розгляду також показник: } \\
K_{B}=\frac{m_{B}^{H}-m_{B}^{\kappa}}{m_{B}^{H}}, \\
\hline
\end{array}
$$

який характеризує відносні втрати сторони $B$. Значення наведених показників на кінцевому етапі бойових дій можна розглядати як критеріальні 


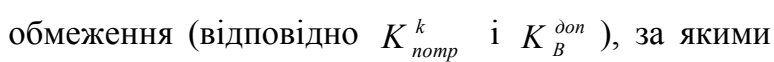
ціль операції досягається.

Тепер, проводячи необхідні перетворення, отримаємо

$$
\left(K^{H}\right)^{4}=\left(K_{\text {nomp }}^{k} f\left(K_{B}^{\text {don }}\right)\right)^{4}+\frac{\lambda_{B}}{\lambda_{A}}\left(1-\left(f\left(K_{B}^{\partial o n}\right)\right)^{4}\right)
$$

Вираз (5) у вигляді біквадратної залежності встановлює математичний зв'язок між необхідним початковим співвідношенням сил сторін $K^{H} \mathrm{i}$ критеріальними обмеженнями. Якщо праві частини рівнянь (1) мають прямопропорційну залежність (лінійний випадок рівняння динаміки середніх), то вираження (5) може бути отримано у вигляді квадратичної залежності.

Необхідно підкреслити, що як у першому, так і у другому випадку вихідне співвідношення сил $\frac{m_{A}^{H}}{m_{B}^{H}}\left(m_{B}^{H}\right.$ - визначається, $m_{A}^{H}$ - задається $)$ забезпечить досягнення мети операції за раніше заданими критеріями на момент ії завершення.

У цьому методичному підході не вирішеним залишається тільки питання визначення необхідного часу на проведення операції (бойових дій), а також побудови еталонного графіка (опорної траєкторії) зміни коефіцієнта співвідношення сил сторін у часі. Для цього потрібно розв'язати систему (1) чисельним способом з урахуванням (5).

Необхідний часовий інтервал ведення бойових дій буде визначати виконання заданих критеріальних обмежень. Цей часовий параметр важливий i 3 точки зору визначення (при

\section{Лimepamypa}

1. Романченко І. С. , Котляров В. П. , Шаповал Ю. С. Чисельна інтерпретація динаміки змінення співвідношення сил сторін під час ведення ними бойових дій // Зб. наук. пр. ЦНДІ ЗС України. Київ, 2008. № 4 (46). С. 11-15. 2. Котляров В. П., Павлюк О. О., Блінов О. В, Кузнєцов О. А. Ідентифікація коефіцієнтів інтенсивності вражаючого конкретному співвідношенні сил за етапами операції) початку введення резервів для подальшого проведення контрнаступу або контрудару. Також вираз (5) є ключовим під час визначення потрібної величини нарощування складу угруповання за рахунок резервних формувань.

\section{Висновки й перспективи подальших досліджень}

Таким чином, запропонований підхід до визначення аналітичної залежності для початкового співвідношення сил сторін із урахуванням критеріальних обмежень дозволяє коректно зробити розрахунок динаміки змінення співвідношення сил сторін із дотриманням вимог до етапів проведення операції, що $\epsilon$ дуже важливим чинником для визначення необхідного складу угруповання військ однієї зі сторін (у загальному випадку). Крім того, цей підхід дозволяє визначити й час ведення бойових дій, а у разі необхідності - і початок введення резерву та потрібну його величину. Алгоритм розрахунків базується на виведенні аналітичного співвідношення, яке $є$ загальним інтегралом системи нелінійних диференціальних рівнянь динаміки середніх.

Подальшим напрямом досліджень слід вважати застосування цього підходу для розрахунку необхідного співвідношення сил у конкретних операціях.

\title{
ОПРЕДЕЛЕНИЕ АНАЛИТИЧЕСКОЙ ЗАВИСИМОСТИ ДЛЯ ИСХОДНОГО СООТНОШЕНИЯ СИЛ СТОРОН С УЧЁТОМ КРИТЕРИАЛЬНЫХ ОГРАНИЧЕНИЙ
}

\author{
Игорь Сергеевич Романченко(доктор воен. наук, профессор) ${ }^{1}$ \\ Владимир Петрович Котляров (доктор техн. наук, профессор) ${ }^{1}$ \\ Александр Алексеевич Павлюк ${ }^{2}$
}

\section{${ }^{1}$ Центральный научно-исследовательский институт Вооруженных Сил Украины, Киев, Украина \\ ${ }^{2}$ Воинская часть А0796, Ровно, Украина}

В статье рассматривается подход, который базируется на анализе системь дифференииильньх уравнений метода динамики средних для определения общей аналитической зависимости соотношения сил сторон с учетом критериальных ограничений.Уравнения динамики средних представлены $в$ нелинейной постановке, когда коэффициенты поражающего воздействия зависят от численности состояний. В статье используются положения теории дифференциальных уравнений для определения общей интегральной свёртки (общего интеграла системы). Критериями достижения цели операции являются величина допустимых потерь одной из сторон, а также необходимая величина соотношения сил сторон на момент завершения операции. С учётом этих критериальных ограничений предлагаемый подход позволяет определить время, необходимое на ведение боевых действий, а также, в случае необходимости, и начальное значение необходимого количества сил одной из сторон для Modern Information Technologies in the Sphere of Security and Defence №3(33)/2018 ISSSN2311-7249(Print)/ISSSN2410-7336(Onfine) 141 
гарантированного достижения цели операции в целом. Интегрирование системы дифференщиальных уравнений позволяет рассчитать эталонный график (опорную траекторию) изменения коэффициента соотношения сил во времени с учётом условий критериальных ограничений.

Ключевые слова: группировка войск (сил), соотночение сил сторон, критериальное ограничение, дифференциильное уравнение.

\title{
DETERMINATION OF ANALYTICAL DEPENDENCE FOR INITIAL RATIO OF FORCES WITH CONSIDERING OF CRITERIA LIMITATIONS
}

\author{
${ }^{1}$ Ihor S. Romanchenko (Doctor of Military Sciences, Professor) \\ ${ }^{1}$ Volodymyr P. Kotliarov (Doctor of Technical Sciences, Professor) \\ ${ }^{2}$ Oleksandr O. Pavliuk \\ ${ }^{1}$ Central research institute of the Armed Forces of Ukraine, Kyiv, Ukraine \\ ${ }^{2}$ Military Unit A0796, Rivne, Ukraine
}

This article considers an approach which is based on the analysis of the system of differential equations of the medium dynamics method to determine the general analytical dependence of the ratio of forces with considering of criterion limitations.

Equations of medium dynamics are considered in the nonlinear formulation, when the coefficients of the effect depend on the number of statuses.

The article describes the approaches of the theory of differential equations to determine the general integral convolution (general integral of the system).

The criteria for achieving the objective of operation are the amount of affordable losses of the one of the sides and the required ratio of forces. Taking into account the criteria limitation, proposed approach allows to determine the required time for conducting an operation, as well as, if necessary, the initial amount of required number of forces of the one of sides for guaranteed achievement of the operations objective.

The solution of the system of differential equations allows us to calculate the reference graph (reference trajectory) of the ratio of forces coefficient changing in time, in accordance with conditions of the criteria limitations.

Keywords: military formations, ratio of forces, criterion limitation, differential equation.

\section{References}

1. Romanchenko I.S., Kotliarov V.P., Shapoval Y.E. Numerical interpretation of the dynamics of the change in the ratio of forces of the sides during the combat actions // The collection of scientific works, The CRI of the AFU, Kyiv, 2008. \# 4 (46) P. 11-15. 2. Kotliarov V.P., Pavliuk O.O., Blinov O.V., Kuznetsov O.A. Identification of the coefficients of the intensity of effect based on the results of numerical calculations. The collection of scientific works, The CRI of the AFU, Kyiv, 20016. \# 3 (77) P. 33-38. 3. Bronshtain I.N., Semendiaev K.A. Mathematical Reference Book for Engineers and Students. Translation from German under edition Groshe I. and Zigler V. Leipzig: Toibner. Moscow: Nauka. The main editorial office of the physical and mathematical literature. $1981.720 \mathrm{p}$. 